\title{
An outline of avalanches in the southeastern Tibet Plateau, China
}

\author{
Wang Yanlong and Huang MaOHuan \\ Lanzhou Institute of Glaciology and Geocryology, Academia Sinica, Lanzhou 730000, China
}

\begin{abstract}
Avalanches are a widespread hazard that cause serious damage in the southeastern Tibetan Plateau. Abundant solid precipitation and high relief are favourable for avalanche occurrence. The monsoon climate brings a lot of precipitation which, however, is not well distributed. Avalanches are most common around the margins of the plateau. Wet snow avalanches occur most frequently. Based on data on precipitation and topographical relief, a map is drawn showing the areal distribution of avalanche hazards.
\end{abstract}

\section{INTRODUGTION}

Avalanches in the southeastern Tibetan Plateau, China, were first studied in 1964, when a group of scientists were sent to Guxiang District, Bomi County, to investigate glacier debris flows (Deng, 1980). Later, in 1981-83, a comprehensive scientific expedition was sent to the Hengduan mountains. At that time two avalanche observation stations were established, one on Baimangxue mountain and one in Bomi District. The areal distribution, types and features of avalanches in this region were described by Wang and Shao (1983, 1984), Wang (1986a,b,c) and Wang and Huang (1986). Avalanche observations along several road sections have been carried out since 1981. The progress of avalanche observations is reviewed in this paper.

The southeastern Tibetan Plateau is taken, in this paper, to include southeastern Tibet Autonomous Region, western Sichuan Province and northern Yunnan Province (Fig. 1). The Daxue, Shaluli, Markam, Baishula and Gaoligong mountain ranges in this region are parts of the Hengduan mountains. The east end of the Nyaiqêntanglha range is situated on the western margin of this region. The main peak of the Hengduan mountains is Mount Gongga (7514 m a.s.1.).

The southeastern Tibetan Plateau is a special region geographically, where neotectogenesis is intense and differences in topographical elevation are great, with high mountains and deep valleys. Precipitation is plentiful in the region due to the southwestern monsoon from the Indian Ocean. The maximum depth of snow cover is always over $2 \mathrm{~m}$. These are advantageous conditions for avalanches, and, thus, they sometimes cause serious damage to economic activities, lives and property. Therefore, it is important to understand avalanche distribution, features and hazards.

Significant climate characteristics in the southeastern Tibetan Plateau are the tremendous horizontal and vertical gradients in various meteorological factors. For example, mean annual air temperature and annual precipitation are about $20^{\circ} \mathrm{C}$ and $1400 \mathrm{~m}$, respectively, in the southern part, and $5^{\circ} \mathrm{C}$ and $700 \mathrm{~mm}$, respectively, in the northern part. Meteorological factors such as air temperature and precipitation also change with altitude. As a result, several climate zones occur between the lower and upper parts of a river basin. Furthermore, vertical variations in meteorological factors are usually greater than the horizontal. This results in peculiar features in the distribution of solid precipitation and variation in length of cold periods. However, as meteorological stations in this region are located generally in river valleys or basins,

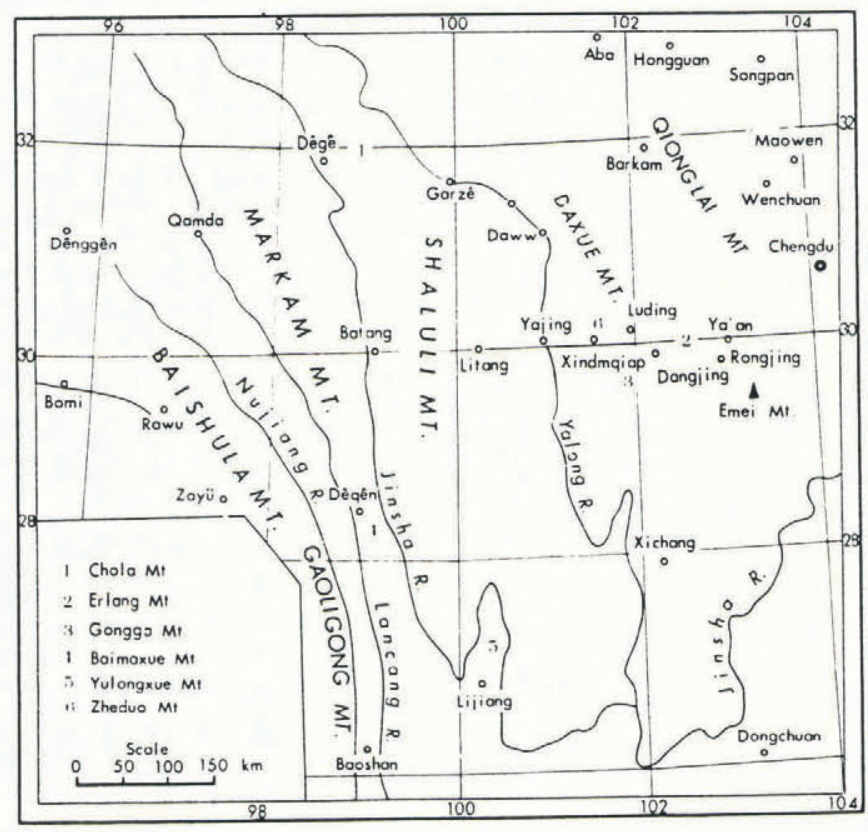

Fig. 1. Map of southeastern Tibetan Plateau. 
extrapolation of climatic data obtained at the stations is necessary to estimate conditions in the alpine zone.

Profile

Lapse rate

$\kappa 100 \mathrm{~m}^{-1}$

$\begin{array}{ll}\text { Batang-Litang } & 0.65 \\ \text { Batang-Yidun } & 1.01 \\ \text { Yajiang-Litang } & 0.70 \\ \text { Yajiang-Xingduqiao } & 1.00 \\ \text { Luding-Ertaizi } & 0.64 \\ \text { Luding-Kangding } & 0.67 \\ \text { Luding-Moxi } & 0.60 \\ \text { Xinduqiao-summit of Zheduo } & 0.59 \\ \text { south slope of Mount Gongga } & 0.65 \\ \text { Jiulong-Jichou } & 0.65 \\ \text { west slope of Mount Gongga } & 0.58 \\ \text { Luhuo-Dawu } & 0.53 \\ \text { Dêgê-Malong } & 0.65 \\ \text { Qamdo-Dêngqên } & 0.65 \\ \text { Barkam-Aba } & 0.86 \\ \text { Barkam-Hongyuan } & 1.10 \\ \text { Wenchuan-Songpan } & 0.51 \\ \text { Wenchuan-Heishui } & 0.86 \\ \text { Lijiang Prefecture } & 0.60 \\ \text { Baoshan Prefecture } & 0.50 \\ \text { Lujiangba-Shangjiangba } & 0.70 \\ \text { Bomi-Guxiang } & 0.65 \\ \text { Zajü-Lhünzê } & 0.43 \\ \text { Garzê-Chola mountain } & 0.67\end{array}$

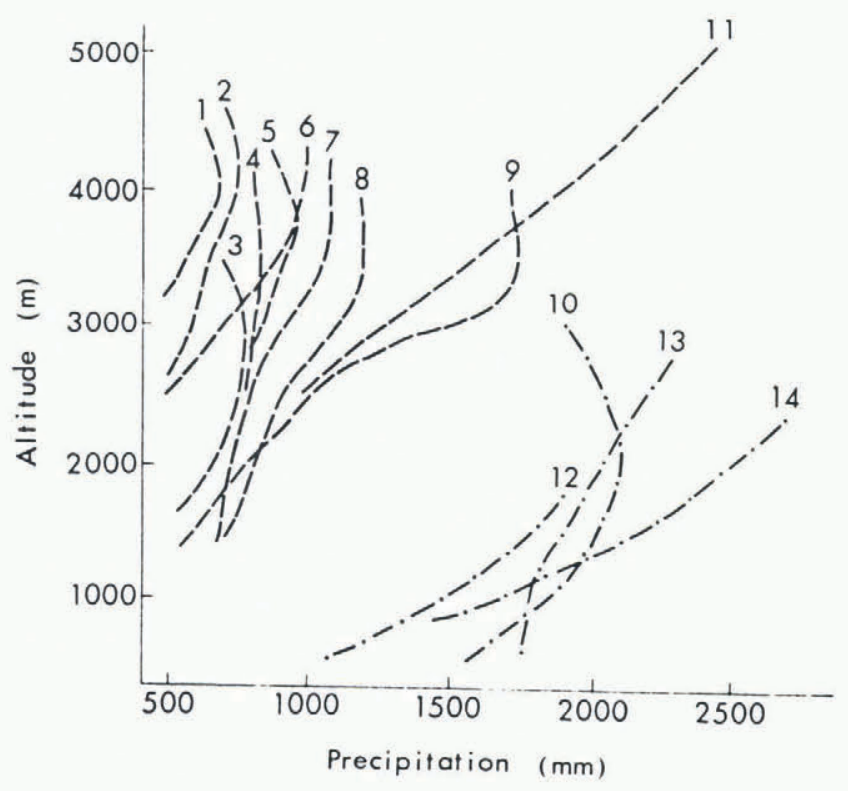

Fig. 2. Generalized profiles of annual precipitation versus altitude in the southeastern Tibetan Plateau. 1, QamdoDêngqên; 2, Chola mountain; 3, Maowen-Hongyuan; 4, Yajiang-Litang; 5, west slope of Mount Zheduo; 6, Batang-Yidun; 7, Luding-Ertaizi; 8, Dongchuan Prefecture; 9, Lijiang Prefecture; 10, Mount Emei; 11, Bomi Prefecture; 12, east slope of Qionglai mountain; 13, $Y_{a}$ 'an-Erlang mountain; 14, Rongjing-Daxiangling.

\section{CONTINUOUS SUB-FREEZING DAYS $\left(\Sigma D^{-}\right)$}

Data on air temperature and precipitation at 125 meteorological stations were available. Among them, data at 2, 3, 96 and 24 of these stations covered 2, 3, 25 to 30 , and $>30$ year periods, respectively. Data on air temperature gradients from more than 20 profiles were collected as well. Air temperature usually decreases with increased elevation, except for one or two valleys with temperature inversions. The lapse rate is quite different from place to place, however (Table 1).

$\Sigma D^{-}$is a measure of coldness. It is defined as the number of continuous days during which the daily mean air temperature is lower than $0^{\circ} \mathrm{C}$. $\Sigma D^{-}$for a site at a known elevation near a meteorological station can be estimated from the station records if the lapse rate is known.

\section{PRECIPITATION CONDITIONS}

Annual solid precipitation varies both horizontally and vertically in the region, but the vertical variation is greatest. In mountainous areas, there is usually a zone of maximum precipitation at an intermediate altitude. It is necessary to know the altitude at which precipitation reaches a maximum and the vertical gradient of precipitation in various areas in order to estimate precipitation in places where no observations are available. Again, meteorological stations are normally located in valleys and basins, not in alpine areas. This makes precipitation analysis difficult. We have 14 records of precipitation change with altitude, using data from meteorological stations together with those from shortterm field observation sites in the alpine zone (Fig. 2). There are two obvious groups of curves in Figure 2, curves 1-8 and 9-14. The former are in areas of lower snowfall, in which precipitation is generally not more than $1200 \mathrm{~mm} \mathrm{a}^{-1}$, and the latter are in areas of heavy snow, in which precipitation exceeds $1200 \mathrm{~mm} \mathrm{a}^{-1}$, with a maximum over $2800 \mathrm{~mm} \mathrm{a}^{-1}$. It also can be seen from Figure 2 that the altitude of maximum precipitation gradually increases from curve 14 to curve 1 , that is, from southeast to northwest.

In general, precipitation increases with altitude below the altitude of the maximum precipitation. Supposing that the increase is linear and is known, we can estimate the amount of precipitation at any altitude near a meteorological station of known altitude. Assume that any precipitation is solid during the period when mean daily temperature is continuously below $0^{\circ} \mathrm{C}$. Then solid precipitation in a seasonal avalanche region during this period can be estimated. Using measured precipitation at 125 meteorological stations, the precipitation during the period when mean daily temperature is continuously below $0^{\circ} \mathrm{C}$ was calculated for 370 sites and the results were contoured (Fig. 3). 


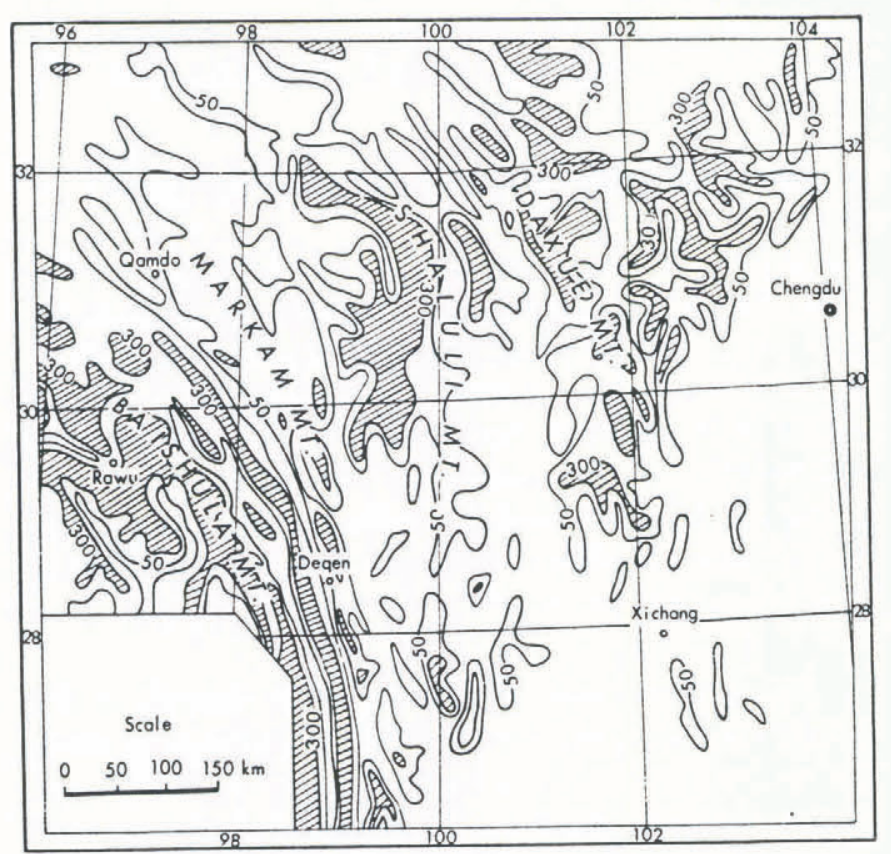

Fig. 3. Contours of annual solid precipitation in the southeastern Tibetan Plateau $(\mathrm{mm})$. (Shaded areas are more than $300 \mathrm{~mm}$.)

\section{TOPOGRAPHICAL CONDITIONS}

The zero isotherm is at an elevation of about $4200 \mathrm{~m}$ in March in this region. There is usually a zone in which seasonal avalanches are common between 3700 and $4600 \mathrm{~m}$. A perennial avalanche area is located above the seasonal one. Large avalanches can run from the perennial avalanche area into the seasonal one.

Topographical relief and angle of slope are important controls on avalanche occurrence. A slope with an angle larger than $60^{\circ}$ or less than $20^{\circ}$ is unfavourable for avalanches because snow does not accumulate or release, respectively. However, large avalanches which cause heavy damage depend not only on slope angle, but also on altitude difference and slope length. Therefore, to evaluate topographic conditions for avalanche occurrence, one must consider slope area as well as angle. We find useful the parameter, $K$, defined by

$$
K=\arctan \left(H P^{-1 / 2}\right),
$$

where $H$ is the altitude difference between the lowest and highest points in a basin, in metres, and $P$ is the basin area in $\mathrm{m}^{2}$. First a river of length between 40 and $60 \mathrm{~km}$ is chosen to represent a medium-sized drainage. Its $P$ and $H$ can be obtained from maps, and $K$ is calculated. The results are contoured (Fig. 4). Values of $K$ were determined for 223 river drainages.

$K$ ranges from 25 to $40^{\circ}$ in this region. Field observations suggest that large avalanches occur only in places where $K$ is over $30^{\circ}$.

\section{TYPES OF AVALANCHES}

Dangerous large avalanches in the southeastern Tibetan

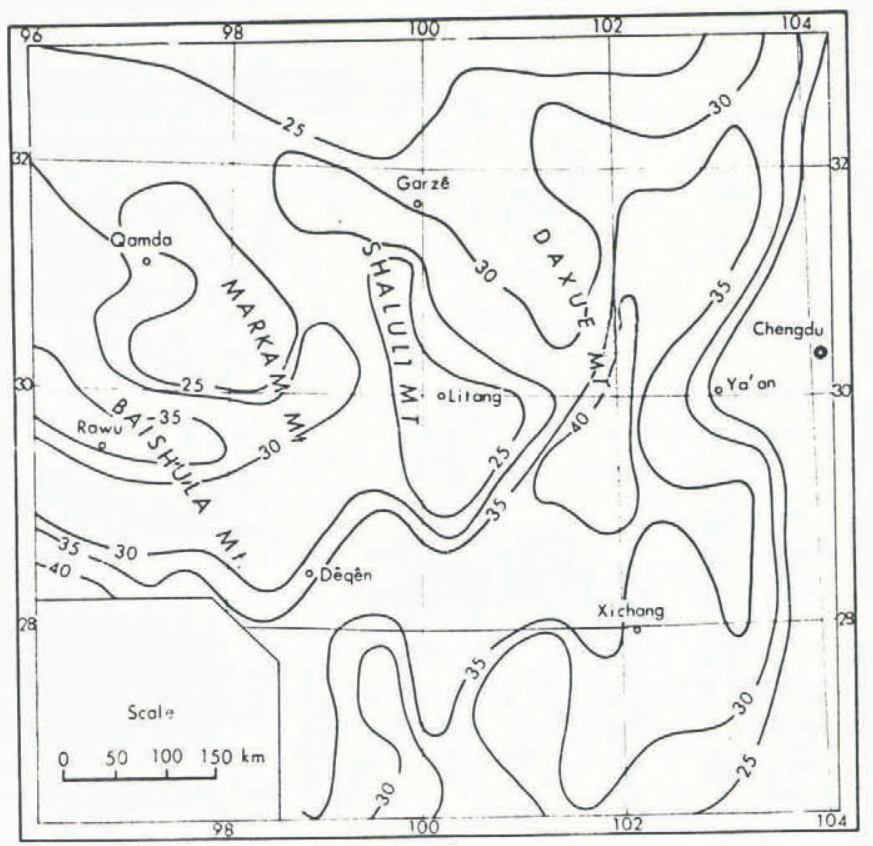

Fig. 4. Contours of the slope steepness parameter, $K$, in the southeastern Tibetan Plateau.

Plateau are mostly wet snow avalanches, although occasionally depth-hoar avalanches (Wang and Huang, 1986) and fresh dry snow avalanches also occur. At elevations over $4000 \mathrm{~m}$, stable snow cover begins to accumulate in October. Once winter begins, avalanches commence as snow depths gradually increase. Field investigations show that wet snow avalanches occur frequently when the mean monthly air temperature is higher than $-3^{\circ} \mathrm{C}$ (Wang, 1986b). When mean daily air temperature is between 2 and $0^{\circ} \mathrm{C}$, successive snowfalls usually lead to wet snow avalanches, particularly in the spring when snowfall is heavy. The first precipitation peak usually occurs in February or March, and in early March the snow depth may reach $150 \mathrm{~cm}$ in the area above $3500 \mathrm{~m}$ a.s.l. At that time, the water content of the snow increases and snow cohesion becomes weak so large wet snow avalanches may break out, even on gentle slopes.

From February or March, the temperature increases and snowfall also increases sharply. Wet snow avalanches occur often, bringing huge amounts of debris and terrific destruction that is rarely seen in other regions of China. With further rise in temperature the zone of avalanche initiation rises. It is possible that more than one avalanche may occur in the same gully or on the same slope in a year.

In the southeastern Tibetan Plateau, the depth-hoar layer is about $0.15 \mathrm{~m}$ thick in the seasonal avalanche area. This is not as thick as in northwestern China, but total snow cover is usually deeper than $0.7 \mathrm{~m}$ and has a relatively high density, higher than $300 \mathrm{~kg} \mathrm{~m}^{-3}$ on the average. Owing to the overburden, the depth-hoar layer collapses easily. Depth-hoar avalanches thus may occur when snow cover exceeds $0.7 \mathrm{~m}$ in depth if a slope is steeper than $35^{\circ}$ (Wang, 1988).

Precipitation in the monsoon region is less during 


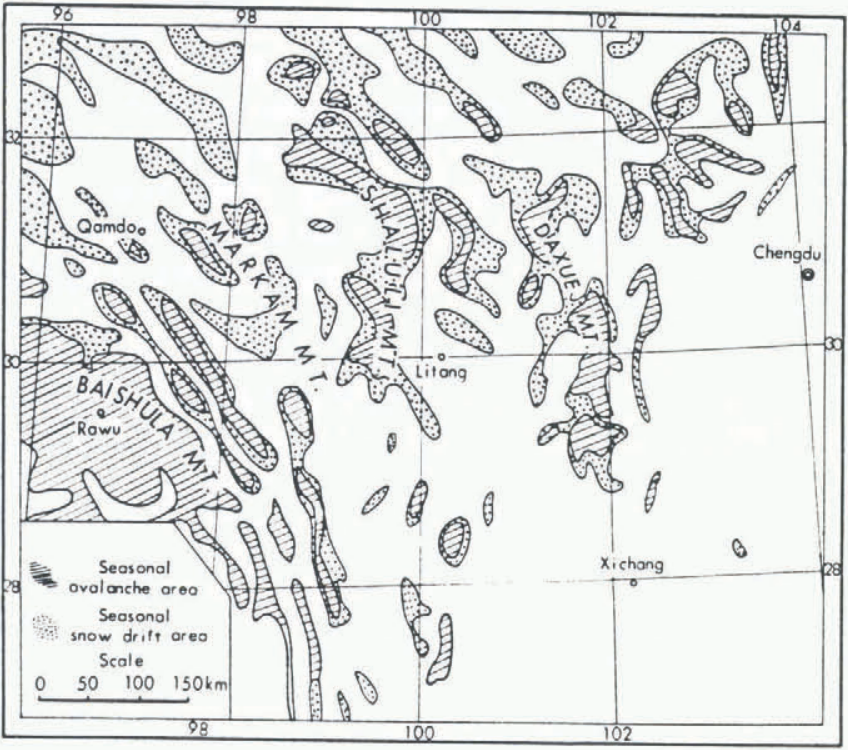

Fig. 5. Distribution of avalanche-prone areas in southeastern Tibetan Plateau. Snowdrift areas are also shown.

midwinter, so avalanches are rarely seen on the plateau in this season. Occasionally, in the case of heavy continuous snowfall, fresh dry-snow avalanches may occur in December, January or early February.

\section{DISTRIBUTION OF AVALANCHES}

From the above discussion it can be seen that the areal and seasonal distribution of avalanches in the southeastern Tibetan Plateau is closely related to solid precipitation, terrain characteristics and air temperature.

Based on the data given in Figures 3 and 4, a map showing the areal distribution of avalanche hazard areas in the southeastern Tibetan Plateau was made (Fig. 5). From Figure 5 it can be seen that avalanches occur mainly on the periphery of the plateau and in its vicinity. In those areas avalanches are serious. They are massive, and cause widespread damage.

In Figure 5, snowdrift areas are also shown. Snowdrifting is another hazard accompanying avalanches in this region. In the area where solid precipitation is more than $150 \mathrm{~mm}$, snowdrifting is widespread. The altitude of the area of severe snowdrifts is also related to $\Sigma D^{-}$and to the amount of solid precipitation. Snowdrift generally occurs in alpine areas higher than $4300 \mathrm{~m}$. However, in alpine areas higher than $4000 \mathrm{~m}$ in Sichuan Province, such as Chola mountain, $\Sigma D^{-}$is longer than 100 days, but there is no particular snowdrift damage there, because the solid precipitation is not greater than $50 \mathrm{~mm}$. At an altitude of $3500 \mathrm{~m}$ in southeastern Tibet Autonomous Region and northern Yunnan Province, where solid precipitation is large, snowdrifting is not serious because $\Sigma D^{-}$is less than 100 days. In these regions snowdrifting is observed only in mountain passes and on mountain ridges higher than $4000 \mathrm{~m}$.

\section{AVALANCHE DAMAGE}

Avalanches are occasionally hazardous for highways, and for communication and power lines. Highway transportation is an economic mainstay in this region. The SichuanTibet and Yunnan-Tibet highways are trunk roads, and they and their branches often suffer avalanche damage. In February 1979, for example, a large avalanche occurred near Highway Maintenance Squad No. 82 on the Sichuan-Tibet Highway. The avalanche debris, about $1 \times 10^{7} \mathrm{~m}^{3}$ in volume and 1 to $5 \mathrm{~m}$ in depth, buried the highway over a $1000 \mathrm{~m}$ stretch.

Avalanches with long runout distances are occasionally seen in this region. For example, in Bomi District, a large avalanche broke out in 1950. The avalanche fell from a summit at $6000 \mathrm{~m}$ a.s.l., passed a glacier, ran across a basin at $3300 \mathrm{~m}$ a.s.l., and then jumped a mountain $4000 \mathrm{~m}$ high. It finally stopped at a great river at an altitude of $2500 \mathrm{~m}$. The forest was destroyed and the farmland buried by snow. The total runout distance was $8 \mathrm{~km}$, with $3500 \mathrm{~m}$ of vertical drop (Deng, 1980). As a consequence of the forest destruction and consequent exposure of loose ground, a big debris flow occurred in this district three years later. As a result, a large area of farmland was buried, several people were killed or injured, and a highway through the disaster area was completely blocked for months.

There are some remote districts in Tibet that have suffered hardships from avalanches. For example, in Mêdog County, which is unique in China as it has no highways, due to frequent avalanches and active snowdrifting, external traffic is blocked for 9 to 10 months of the year.

Avalanches are hazardous for mountaineering and tourism. In alpine zones, avalanches may occur at any time. Avalanche gullies are often convenient routes to climb to a summit, but these are also dangerous routes, and mountaineers are frequently killed by avalanches. For instance, eight Japanese mountaineers were buried in an avalanche on Mount Gongga in May 1981.

\section{ACKNOWLEDGEMENTS}

We are grateful to Ren Jiawen, Gao Xiangqun, Jin Zhengmei and Wang Xiaoxiang, who gave us great help in preparing this paper.

\section{REFERENCES}

Deng Yangxin. 1980. Snow avalanche in Guxiang region of Xizang and its role in the physical geographic processes of high mountains. Acta Geographica Sinica, 35(3), 242-250. [In Chinese with English abstract.]

Wang Yanlong. 1986a. A wet snow avalanche with heavy harmfulness in China. 7. Glaciol. Geocryol., 8(1), 52-60. [In Chinese with English abstract.]

Wang Yanlong. 1986b. Dry-snow avalanche in China. $\mathcal{F}$. Glaciol. Geocryol., 8(4), 381-387. [In Chinese with English abstract.]

Wang Yanlong. 1986c. Some physical properties of seasonal snow cover in northern Yunnan and western 
Tien Shan mountains. In Proceedings of the Second National Conference on Glaciology of the Geographical Society of China. Lanzhou, People's Publishing House of Gansu, 173-179. [In Chinese with English abstract.]

Wang Yanlong. 1988. The relation between the growth of seasonal depth hoar and the avalanches in China. $\mathcal{J}$. Glaciol. Geocryol., 10(2), 173-180. [In Chinese with English abstract.]

Wang Yanlong and Huang Maohuan. 1986. An outline of avalanches in China. Cold Reg. Sci. Technol., 13(1), 11-18.
Wang Yanlong and Shao Wenzhang. 1983. A preliminary study on snow calamities in west Sichuan, north Yunnan and southeast Xizang. Mountain Research, 1(4), 17-21. [In Chinese with English abstract.]

Wang Yanlong and Shao Wenzhang. 1984. Avalanches and glacier at Hailuogou in the Mt Gongga. 7. Glaciol. Cryopedol., 6(2), 37-44. [In Chinese with English abstract.]

The accuracy of references in the text and in this list is the responsibility of the author/s, to whom queries should be addressed. 